\title{
Congratulations to Ya. G. Smorodinskii
}

DOI: $10.1134 / \mathrm{S} 1061830908110107$

Yakov Gavrilovich Smorodinskii was born on November 28, 1948, in Nizhni Tagil. In 1973, he graduated from the Physicotechnical Faculty of the Ural Polytechnical University and, since that time, has worked at the Institute of Metal Physics of the Ural Division of the Russian Academy of Sciences. Smorodinskii began his activity as a junior researcher and now is the head of a laboratory. He holds the titles of doctor of engineering and professor.

Smorodinskii's scientific interests include studies of the propagation of ultrasonic waves in anisotropic and inhomogeneous media. These investigations are aimed at the development of new ultrasonic nondestructive testing techniques. Smorodinskii is the author of five monographs and more than 70 scientific publications in Russian and foreign journals. In 2004 , as a member of a team of authors, he was awarded the State Prize of the Russian Federation in the field of science and technology.

The editorial board of our journal, in whose work Smorodinskii has participated for many years, and the scientific community cordially congratulate him on his 60th birthday and wish him good health and further creative achievements.

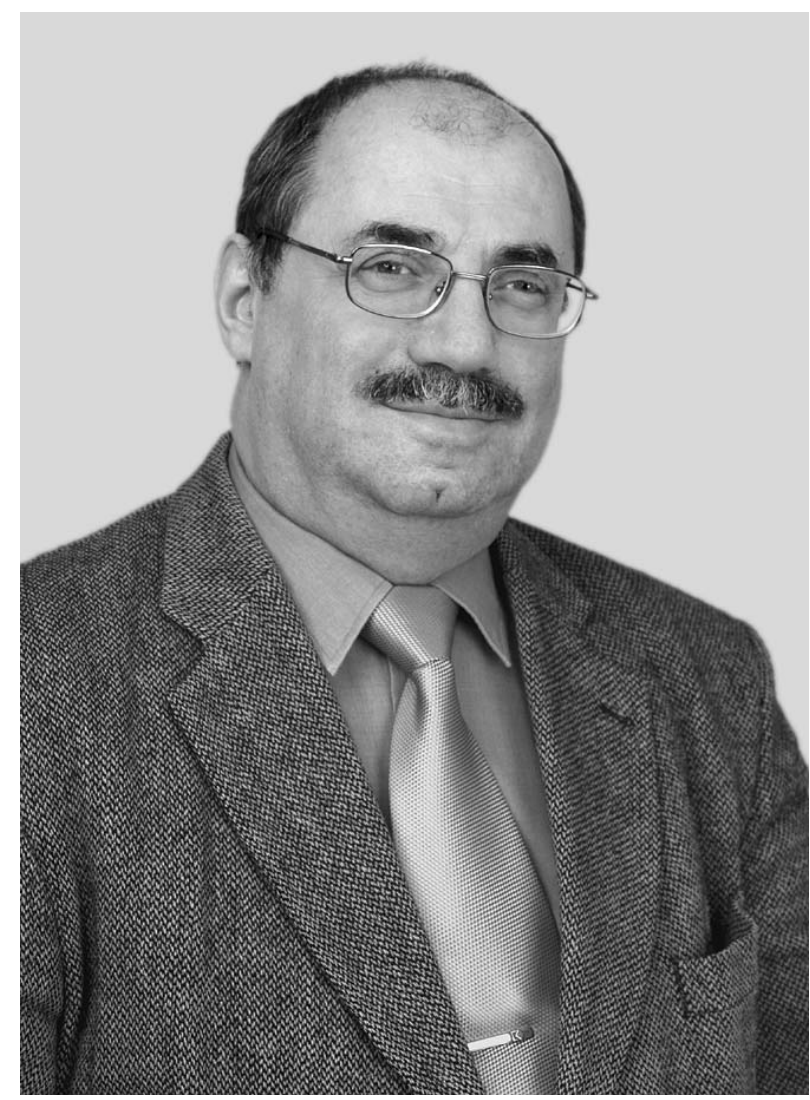

